\title{
AS TECNOLOGIAS DA INFORMAÇÃO E COMUNICAÇÃO NA EDUCAÇÃO - PROJETO RÁDIO-ESCOLA
}

\author{
Sirlene de Castro Oliveira* \\ Telma Maria Santos Castilho**
}

\begin{abstract}
RESUMO
Esta pesquisa foi desenvolvida em uma instituição da rede pública de Uberaba/MG e se constitui na incorporação das Tecnologias da Informação e Comunicação na escola. Visa apresentar algumas considerações sobre o uso do rádio como veículo de comunicação e ferramenta de apoio pedagógico na formação do conhecimento e aplicação de novas abordagens de ensino e estratégias pedagógicas. Para tanto, montou-se uma Rádio-escola formada por uma equipe de vinte e três alunos do ensino fundamental e médio, que de forma alternativa (presencial e on-line) aborda temas como: ética, cidadania, afetividade e sexualidade, preservação do meio ambiente, globalização, a mídia e sua influência na vida das pessoas, dentre outros. Por meio da produção e apresentação de programas de rádio, o aluno participa diretamente e ativamente do processo de ensinoaprendizagem.
\end{abstract}

PALAVRAS-CHAVE: Educação. TICs. Rádio-escola

\footnotetext{
* Mestre em Educação pela Universidade Federal de Uberlândia e coordenadora do Curso de Pedagogia da UNIPAC de Uberaba. E-mail: sirlenecastro@yahoo. com.br

** Especialista em Docência na Educação Superior pela UFTM e professora de pesquisa educacional da Escola Estadual Professora Corina de Oliveira. E-mail: telcastilho@gmail.com
} 


\begin{abstract}
This research was developed into an institution of the public net of Uberaba/MG and constitutes the incorporation of the Technologies of the Information and Communication in the school. It aims at to present some considerations about the use of the radio as communication vehicle and tool of pedagogical support in the formation of the knowledge and application of new boardings of education and pedagogical strategies. For in such a way, a Radioschool formed for a team of twenty-three students of the elementary and high school was mounted, that of alternative form (one having a face to face type of learning and another talking place through the internet) it approaches subjects as: ethics, citizenship, affectivity and sexuality, preservation of the environment, globalization, the media and its influence in the life of the people, amongst others. By means of the production and presentation of radio programs, the student participates directly and actively of the teach-learning process.
\end{abstract}

KEYWORDS: Education. ICTs. Radio-school

\title{
1. INTRODUÇÃO
}

Quando se fala em Tecnologias da Informação e Comunicação (TICs) na formação inicial de professores, principalmente os que trabalham nas escolas da rede pública, surgem situações-problema e crenças errôneas a respeito da utilização correta dessas tecnologias no desenvolvimento de suas atividades docentes.

É indubitável que a maioria das escolas que se dizem detentoras de uma gestão democrática pregam o uso das TICs como ferramenta de apoio pedagógico e fator motivacional na produção e transmissão do conhecimento no desenvolvimento de habilidades e competências dos seus alunos.

Parece contraditório, mas a escola pode se enganar e muito 
acerca dessas afirmações. Atualmente muito se fala em inovação pedagógica, tecnológica, valorização profissional e humana, participação ativa dos alunos e gestão democrática, mas muitas escolas acabam por esquecer que o papel determinado a cada um se projeta nas ações efetivas que demonstrem essa condição.

Vamos falar um pouco do que entendemos como "participação ativa", nessa questão. Visualize um ambiente escolar delineado pela integração da informação por meio de uma rádio-escola comandada exclusivamente pelos alunos, onde a programação está voltada para a realidade da comunidade escolar e os programas são transmitidos no início das aulas e durante o recreio.

Quando afirmamos que isso é possível e que vem acontecendo há mais de dois anos por meio de uma pesquisa desenvolvida em uma escola da rede pública, quase sempre o maior questionamento feito pelos professores é em relação ao uso de alguns minutos das aulas para a transmissão dos programas e o fato destes serem produzidos exclusivamente pelos alunos.

É necessário compreendermos que, neste caso, existe uma grande barreira no exercício da comunicação, pois fica evidente que esses educadores ainda utilizam em suas práticas educativas aquele modo "arcaico" de professor como detentor absoluto do conhecimento que privilegia um aprendizado metódico, padronizado, sem significado para o aluno.

Atualmente, a tecnologia educacional é uma realidade nas escolas, porém faz-se necessário criar ambientes facilitadores que incluam nova postura da escola, novas atitudes docentes, com metodologias que permitam a participação ativa do aluno no processo educacional. O maior desafio, hoje, nas instituições de ensino, é usar a tecnologia de forma inteligente e eficiente na produção do conhecimento, mas até que ponto isso é realmente possível?

O presente artigo constitui-se na versão sintetizada da pesquisa que iniciamos ainda na faculdade durante o curso de graduação em Pedagogia na Universidade Presidente Antônio Carlos (UNIPAC) e

Educ. e Filos. Uberlândia, v. 23, n 45, p. 259-276, jan./jun. 2009 
concluímos no decorrer do curso de Especialização em Docência no Ensino Superior da Universidade Federal do Triângulo Mineiro (UFTM), ambas em Uberaba.

Para realizar o trabalho montamos uma rádio-escola, capacitamos um grupo de vinte e três alunos do ensino fundamental e médio para responsabilizarem-se pela produção e divulgação dos programas. Procuramos observar o papel destes como produtores e transmissores do conhecimento por meio do rádio e a receptividade dos alunos, professores, funcionários e administradores da escola.

Verificamos também, por meio de gravações e filmagens o modo como professores e alunos se posicionam ou são posicionados frente às TICs na escola, seus anseios e suas angústias.

Realizamos observações do comportamento dos alunos em sala de aula e durante o recreio quando a rádio estava "no ar" e fora "do ar", bem como entrevistas para coleta de dados, procurando identificar seus hábitos de estudo na tentativa de compreender os processos de ensinar e aprender fazendo uso das TICs. Discutimos ainda, o projeto com os professores e a administração da escola para aprovação e implantação da rádio-escola.

O fator principal de termos escolhido o rádio como mídia central dessa pesquisa é justamente o fato dele ser uma ferramenta pedagógica que trabalha de forma ampla: com o computador, a fotografia, a televisão, o jornal. Para produzir um programa de rádio, o aluno faz pesquisa utilizando a internet, lê jornais e revistas, assiste $\mathrm{TV}$, tira fotografias, enfim, interage com diversas tecnologias.

\section{Aplicação da Tecnologia à Educação}

A sociedade do conhecimento e da informação apresenta atualmente oportunidades significativas para o uso das TICs na educação. As tecnologias nos ajudam a realizar o que já fazemos ou desejamos com mais interesse e se tivermos propostas inovadoras, facilitarão a mudança. E melhor ainda, com participação ativa dos 
principais interessados (alunos), pois estes têm verdadeira motivação no que diz respeito ao uso das tecnologias na aprendizagem, já que por mais desprovido que seja, o aluno detém algum conhecimento tecnológico. A criança que chega à escola já tem acesso às mídias e passa longo tempo em frente à televisão, utiliza computadores, navega na internet, ouve rádio e $\mathrm{CD}$, joga games. É esse o seu perfil e a escola não pode ignorar o seu conhecimento.

Vivemos em um momento histórico-cultural que nos remete à necessidade de parar e refletir sobre qual direção tomar. Há propostas as mais diversas, em todas as partes para se encontrar um parâmetro, a fim de que as novas gerações estejam preparadas para aprender e, sobretudo, aprender a aprender por toda a vida. Isso pode indicar a possibilidade de uma nova concepção do que seja educar. Diante de uma realidade globalizada, marcada por discriminação e injustiças, faz-se necessária uma real afirmação e concretização do princípio constitucional da igualdade. Percebemos que o mundo precisa urgentemente de mudanças e a construção de uma sociedade democrática, igualitária e justa é algo muito mais complexo do que se pensa, pois abrange a questão ética de cada um.

As TICs vêm influenciando nossas vidas em uma dimensão considerável, principalmente a televisão, o computador (conectado à internet) e o rádio com grande poder de disseminar idéias e valores. Podemos dizer que eles "educam" informalmente as pessoas.

A escola não pode mais ignorar esses meios de comunicação, uma vez que já detêm a função de comunicar com as pessoas, captar suas ansiedades e desejos. Precisa sim, saber utilizá-los em prol de uma educação de qualidade que favoreça a democracia e a integração social. Moran (2000, p. 11) alerta:

Muitas formas de ensinar hoje não se justificam mais. Perdemos tempo demais, aprendemos muito pouco, desmotivamo-nos continuamente. Tanto professores como alunos temos a clara sensação de que muitas aulas convencionais estão ultrapassadas.

Educ. e Filos. Uberlândia, v. 23, n 45, p. 259-276, jan./jun. 2009 
Mas para onde mudar? Como ensinar e aprender em uma sociedade mais interconectada?

Para obtermos resultados satisfatórios com o uso destas tecnologias, precisamos ter clareza das intenções e objetivos pedagógicos das possíveis formas de utilização no aprimoramento e construção do conhecimento. $\mathrm{E}$ isso passa necessariamente por uma educação específica a qual se concretiza efetivamente no ensino superior. É fundamental a preparação acadêmica para o uso adequado das novas tecnologias nos ambientes escolares, principalmente nos cursos de Pedagogia que formam profissionais para atuarem em várias instâncias do sistema educacional.

Para Masetto (2000, p. 135), ainda hoje, no ensino superior, o uso de tecnologia adequada ao processo de aprendizagem não é tão comum, o que faz com que os novos professores do ensino fundamental e médio, ao ministrarem suas aulas, praticamente copiem o modo de fazê-lo e o próprio comportamento de alguns de seus professores de faculdade, dando aula expositiva e, às vezes, sugerindo algum trabalho em grupo com pouca ou nenhuma orientação.

De nada adianta para a escola fazer uso do rádio, por exemplo, sem um objetivo bem definido a ser alcançado e um acompanhamento pedagógico eficaz das atividades que envolvem essa tecnologia. A rádio-escola tem o poder de sensibilizar e motivar os alunos através de constantes e novos desafios, possibilitando o crescimento individual e coletivo, promovendo a inclusão social e oportunidades de qualificação para o trabalho. Quando as atividades que envolvem o uso da rádio-escola são direcionadas para a pesquisa, tornam-se ainda mais significativas, pois o aluno tem prazer em pesquisar para produzir um programa de rádio, o que favorece o processo de ensinoaprendizagem.

A interação humana na comunicação é fundamental no processo educativo. A relação professor-aluno ocorre em via de 
mão-dupla: um fala, o outro responde, existe um intercâmbio de informações. Nesse aspecto, a comunicação torna-se mediadora das tecnologias criando novas alternativas e possibilidades de comunicação. Infelizmente, na maioria das escolas, ainda prevalece a comunicação vertical, centrada no saber do professor como poder. O modelo de escola tradicional ainda prevalece como um modelo de se fazer, vista pelo aluno como um ambiente austero, conservador, cerimonioso e nada empático. Caracteriza-se pela disciplina rígida e pela reprodução dos modelos de transmissão do conhecimento. Apresenta-se como único lugar em que se tem acesso ao saber, onde o aluno é visto como um mero receptor do conhecimento e não participa ativamente do processo de ensino-aprendizagem.

A incorporação das TICs na escola contemplam, portanto, a aplicação de novas abordagens de ensino e estratégias pedagógicas pois exige novas posturas do professor e da escola.

Para Sampaio; Leite (1999, p. 15) o papel da educação deve voltar-se à democratização do acesso ao conhecimento, produção e interpretação das tecnologias, suas linguagens e conseqüências. $\mathrm{O}$ professor precisa estar preparado para trabalhar com as TICs na escola encarando a educação e sua função social com maior abrangência.

\section{A rádio como ferramenta de apoio pedagógico}

Como afirmamos anteriormente, o fator principal de termos escolhido o rádio como mídia central dessa pesquisa é porque ele é uma ferramenta pedagógica que trabalha de forma ampla com diversas tecnologias, além do enorme alcance que o mesmo tem em todo país por ser um meio de comunicação bastante difundido evolvendo praticamente todas as camadas da população e por ser um veículo de comunicação relativamente barato. O surgimento do rádio é considerado umas das grandes revoluções ocorridas na comunicação de massa que teve como seu antecedente o fonógrafo de Edison, que conseguiu gravar e conservar a voz humana. Essa

Educ. e Filos. Uberlândia, v. 23, n 45, p. 259-276, jan./jun. 2009. 
nova forma de mídia permitiu quebrar alguns paradigmas existentes na época, passando com isso, a ser uma mídia alternativa em relação ao jornal e ao papel impresso em geral.

Não existe uma concordância mundial a respeito de quem inventou o rádio. Sabe-se que a existência de ondas eletromagnéticas que se propagam no espaço foi demonstrada, teoricamente, pela primeira vezem 1870, pelo físico inglês James Maxwell, e comprovada empiricamente pelo alemão Heinrich Hertz, em 1888. A história oficial atribui sua utilização prática na comunicação à distância ao italiano Guglielmo Marconi, que fez a sua primeira apresentação da comunicação sem fio em 1896. A primeira transmissão de voz por ondas eletromagnéticas foi atribuída ao canadense Reggie Fasseden. Segundo Júnior (1999), se resgatarmos um pouco da nossa história, foi no Brasil que se deram de fato as primeiras experiências com radiotransmissão, realizadas pelo padre brasileiro, Landel de Moura, nascido em Porto Alegre, em 1861.

Inicialmente o rádio era utilizado apenas como técnica de comunicação a distância, ampliando seu uso ao final da $1^{a}$ Guerra Mundial. A empresa Westinghouse - fábrica de aparelhos eletrônicos localizada nos EUA - foi responsável, meio que por acaso, pelo surgimento da radiodifusão. Ela fabricava aparelhos de rádios para tropas durante a $1^{\text {a }}$ Guerra Mundial, e com o término do conflito, ficou com uma enorme quantidade de aparelhos estocados. Para evitar o prejuízo foi instalada uma antena na própria fábrica para transmitir música aos moradores das proximidades que comprassem os aparelhos de rádio. Dessa forma, todo o estoque foi comercializado e o rádio encontrou seu espaço na sociedade.

Além dos benéficos da rádio-escola citados anteriormente ela propicia aos alunos a expressão de idéias, a produção de conhecimento, a informação, a comunicação e a integração social. Estimula, ainda, o pensamento crítico em relação a influência da mídia na vida das pessoas, inclusive no desenvolvimento da formação da cidadania, propiciando espaço ao jovem para não só ouvir especialistas, mas 
também discutir sobre sensações, emoções e os conflitos existentes nos relacionamentos interpessoais. Percebendo, dessa forma, a si próprio, reconhecendo e respeitando seus sentimentos e dos outros.

A produção do conhecimento com autonomia, com criatividade, com criticidade e espírito investigativo provoca a interpretação do conhecimento e não apenas a sua aceitação. Portanto, na prática pedagógica o professor deve propor projetos que provoquem um estudo sistemático, uma investigação orientada, para ultrapassar a visão de que o aluno é produto e objeto, e torná-lo sujeito e produtor do próprio conhecimento (BEHRENS, 2000, p. 86).

A rádio assume um papel poderoso de catalisador da melhoria e inovação do processo ensino-aprendizagem que é o trabalho em equipe. O professor que nunca fez uso do computador e internet em suas aulas, por exemplo, pode começar pela reflexão acerca dos próprios processos de aprendizagem. Compreendendo como ele próprio aprendeu e o que mudou em sua aprendizagem com a tecnologia, poderá desenvolver estratégias para trabalhar com seus alunos. Dessa forma, quando a rádio entra "no ar", o professor pode sugerir sites de pesquisa para aprofundar o aprendizado a respeito de um tema específico bem como demonstrar que o processo de ensino-aprendizagem é potencializado quando se trabalha em redes colaborativas.

Com o avanço da globalização, faz-se necessário aprender a aprender, saber raciocinar, ser crítico e analítico. Esse deve ser um dos aspectos fundamentais da educação, e é dentro dessa perspectiva que o projeto "Rádio-escola" deve ser pensado.

A rádio-escola leva o professor a refletir sobre sua prática em sala de aula, pois exige uma nova postura que o leva a buscar novas formas de aprender e se apropriar criticamente das informações transmitidas e ser um mediador dessas informações para os alunos levando-os a desenvolver a reflexão sobre a linguagem e a programação radiofônica. 
A rádio propicia ainda, principalmente com o uso da internet, a expansão do acesso à informação atualizada para promover a comunicação a diversas áreas da educação. Segundo Lemos (2004, p. 101), a informática permite aliar o conhecimento da natureza às formas de funcionamento da sociedade moderna, pois cria-se a possibilidade de leitura da realidade, traduzida pela linguagem digital, automatizando a informação. Por meio da criação de sites colaborativos, a escola pode divulgar o trabalho produzido, permitindo, assim, estabelecer novas relações com o saber que ultrapassam os limites da educação tradicional e rompem com os muros da escola, gerando mudanças significativas em seu interior. $\mathrm{O}$ espaço escolar se torna mais aberto e flexível, propiciando a participação ativa entre professores e alunos, entre eles e outras pessoas no interior e exterior da escola, tornando-a mais viva e dinâmica, pois a expõe a críticas legitimando o processo de ensino-aprendizagem.

A utilização do rádio como recurso didático exige que o professor seja criativo, conheça as características e peculiaridades dessa ferramenta. Provoca, também, a superação dos modelos tradicionais de ensino, incorporando inovações e novas formas de ensinar que satisfaçam as necessidades da sociedade nessa nova conjuntura, constituída pelo avanço tecnológico.

Essa nova sociedade pós-industrial, também chamada sociedade do conhecimento, requer novas competências e novas posturas, exigindo um indivíduo participativo, pesquisador, capaz de pensar criticamente e de construir sua autonomia intelectual. Cabe então à escola, enquanto instituição responsável pela formação do sujeito, formar pessoas capazes de lidar com o avanço tecnológico, colocando o educando em contato com as TICs de forma apropriada, bem como colocar a tecnologia a serviço da educação.

É notório que a velocidade com que se propaga a informação e o acesso à mesma não garante a sua efetiva conversão em conhecimento. Aos alunos é disponibilizado o acesso às informações, mas raramente à produção das mesmas.

Educ. e Filos. Uberlândia, v. 23, n 45, p. 259-276, jan./jun. 2009. 
A rádio-escola oportuniza ao aluno comunicador (que produz e apresenta os programas) produzir, reelaborar e compartilhar sua própria informação. Por meio de pesquisas em diversas mídias ele precisa direcionar os programas para o interesse do público alvo, ou seja, alunos e professores. Se isso não ocorrer a programação deixa de ser atrativa e não atinge um dos principais objetivos dos programas de rádio que é informar pelo entretenimento. Desta forma, o aluno "produz" as notícias da própria escola promovendo a coletividade. Torna-se descobridor, transformador e produtor do conhecimento, contemplando uma aprendizagem colaborativa.

A força e o poder da rádio-escola surpreende a todo momento, pois a informação repercute de forma instantânea, direta e indiretamente. Um ouve, fala para o outro e todos acompanham o fato, num curto espaço de tempo. Consegue atingir todas as faixas etárias, mobilizar e agitar a escola, unir e politizar os alunos.

O caminho para que uma rádio-escola cumpra o seu papel educativo é ampliar a cada dia os serviços à comunidade escolar e preservar a confiança do ouvinte (alunos, professores e funcionários) na veiculação da mensagem. É importante a escola entender que a prestação de serviço educacional por intermédio do rádio possui grande força e poder. $\mathrm{O}$ rádio tem a magia de cativar e seduzir os alunos, conduzindo-os a atitudes e comportamentos conforme o sugerido pela equipe, o que lhe possibilitará resultados positivos se forem bem canalizados com as propostas de mudança e transformação.

\section{A rádio-escola sob o olhar do aluno}

As primeiras reações que a rádio despertou nos alunos foram: alegria, entusiasmo, liberdade de expressão, vontade de participar, admiração pela equipe que produz e apresenta os programas. Ao fazer uso da rádio como recurso pedagógico facilitamos um clima de interação pessoal e grupal que ultrapassa o conteúdo e estimula a auto-estima construindo um referencial rico de conhecimento e

Educ. e Filos. Uberlândia, v. 23, n 45, p. 259-276, jan./jun. 2009 
emoções por meio da prática.

Pedimos para alguns alunos, integrantes da equipe de produção que escrevessem ou falassem sobre a rádio-escola e ficamos surpresos com as declarações, tamanho entusiasmo demonstrado. A título de exemplificação, a transcrição da fala de uma aluna do ensino médio

Quando falo da rádio não lembro dos aparelhos, do estúdio. Quando falo da rádio me lembro dos momentos que já passei. Me lembro dos meus amigos, da minha equipe, equipe que coloquei no coração e defendo com unhas e dentes. A rádio é mais que algo para o meu futuro, é parte da minha vida! São momentos e experiências que eu vou contar para meus filhos e netos. A rádio significa momentos bons e felizes, que eu vou guardar para sempre no meu coração (entrevista concedida por Gleisse Alcântara - aluna do $1^{\circ}$ ano do ensino médio).

Percebemos que o grande diferencial da rádio-escola na Escola Estadual Professora Corina de Oliveira é justamente a participação ativa dos alunos desde a escolha por meio de votação do nome da rádio "Rádio Corina" e da mascote "Ed Duca de Oliveira", o slogan que é sucesso dentro e fora da escola "Rádio Corina em sintonia com a educação", a cobertura de eventos fora da escola para publicação de matérias no site "http://www.corina.br22.com" e principalmente a produção e apresentação dos programas com orientação pedagógica, feita exclusivamente pelos alunos.

A programação diária é bem diversificada:

- "Fala aí professor". Um programa de entrevistas dedicado especialmente aos professores da escola;

- "Agenda Cultural" com os principais eventos da cidade;

- "Informativo Corina" um programa de informações no qual os alunos ficam sabendo o que acontece na escola Corina, em Uberaba e no mundo. O diferencial do 
programa é justamente o fato de ser totalmente "ao vivo". Exige a participação de praticamente todos os integrantes da equipe, pois é muito dinâmico e precisa acompanhar a velocidade das informações;

- "Canal do aluno", dedicado especialmente aos alunos da escola com espaço para discussões e idéias inovadoras;

- "PaparazzoCorina". Um programa divertido que apresenta notícias envolvendo funcionários $\mathrm{e}$ alunos. $\mathrm{E}$ tem $\mathrm{o}$ seguinte slogan: "Cuidado! Fique de olhos bem abertos, pois ninguém está livre de ser fisgado pelo Paparazzo".

E ainda, programas eventuais como o "Tema do dia é...", "Rádio-novela", "Plantão Corina", além dos programas de músicas e recadinhos disponíveis diariamente na programação durante o recreio. A rádio funciona nos três turnos: matutino, vespertino e noturno e os programas com duração de no máximo cinco minutos, são apresentados no início das aulas e durante o recreio.

Os alunos da equipe de produção fazem a cobertura dos principais eventos da escola e de vários eventos da cidade ligados ao setor educacional. Já estiveram presentes em universidades, escolas, teatros, etc. Inclusive em outras cidades, acompanhando eventos como: as Olimpíadas de matemática, Química e Física em São Carlos/SP; o Encontro Regional dos Gestores Escolares de Minas Gerais em Sacramento/MG.

\section{A formação da equipe de produção}

Como usuário da rádio-escola, o aluno deverá ser iniciado como pesquisador e investigador para produzir os programas. Nesse contexto, são imprescindíveis orientações e treinamentos por meio de cursos de capacitação periódicos, o que requer disponibilidade e vontade dos profissionais da educação. A escola precisa fazer 
parcerias com Universidades ${ }^{1}$ no sentido de promover palestras, cursos e oficinas com temas específicos relacionados a ética pessoal e profissional e direcionados à produção de programas radiofônicos. Para Moran (2000, p. 63):

Necessitamos de muitas pessoas livres nas empresas e nas escolas, que modifiquem as estruturas arcaicas e autoritárias do ensino escolar e gerencial. Só pessoas livres, autônomas - ou em processo de libertação - podem educar para a liberdade, podem educar para autonomia, podem transformar a sociedade. Só pessoas livres merecem o diploma de educador.

Ensinar fazendo uso das TICs será eficaz se mudarmos nossa forma de encarar o ensino. Enquanto novas posturas não forem assumidas frente ao novo e deixar de lado as formas convencionais que mantêm distantes professores e alunos, a educação não avançará o suficiente. Somente o ensino verdadeiramente significativo para o aluno é capaz de promover transformações.

Os alunos participantes, por meio de curso de capacitação, conhecem todo o processo de produção de programas de rádio. Entre os cursos e oficinas oferecidos estão: Ética e Cidadania, Locução e técnica em rádio, Relacionamento interpessoal, Oratória, Português: gramática e interpretação de textos, Análise crítica da mídia.

Torna-se importante considerar que a regra geral da linguagem radiofônica dentro de uma rádio-escola, deve ser seguida à risca, ou seja, utilizar-se de linguagem clara, direta, correta, objetiva e agradável, sendo imprescindível também uma fala pautada na ética e no respeito à diversidade cultural.

Para Porchat (1993), a notícia deve responder às perguntas: o quê? (o assunto), quem? (personagens envolvidos), onde? (local onde

1 A Universidade Presidente Antônio Carlos - UNIPAC/Uberaba é grande incentivadora disponibilizando professores e alunos estagiários para os cursos de capacitação da Equipe de produção dos programas.

Educ. e Filos. Uberlândia, v. 23, n 45, p. 259-276, jan./jun. 2009. 
acontece o fato), quando? (data, hora), como? (modo como aconteceu o fato), por quê? (causas). A mensagem radiofônica precisa ser envolvente, chamar a atenção, fazer com que o ouvinte participe emocionalmente da mensagem. O rádio é basicamente emoção e o único recurso com o qual ele conta é o som. A fala, a palavra, é a base informativa que, se bem utilizada, é capaz de cativar o receptor. Por isso, algumas dicas de redação são importantes. A estrutura gramatical e lingüística:

- precisa ser linear, observando um desenvolvimento lógico da idéia.

- formar frases sempre em ordem direta, isto é, sujeito, verbo, complemento.

- usar frases curtas e sintéticas. Ir direto ao assunto é um dos princípios básicos do discurso radiofônico.

- evitar monotonia intercalando frases simples com outras um pouco mais longas.

- buscar sinônimos para palavras difíceis e compridas.

- usar o verbo sempre no presente do indicativo quando se tratar de texto jornalístico, isso vai demonstrar instantaneidade e atualidade, características do rádio.

- preferir o singular ao plural, quando não alterar o significado.

- evitar o uso de figuras de linguagem que não estejam incorporadas ao uso comum.

- utilizar vocabulário simples evitando cacófatos ou a repetição de palavras

- evitar expressões que se contradizem e expressões redundantes.

\section{Considerações finais}

Ao fazer uso da rádio como recurso educativo, a escola estimula não apenas os alunos, mas também professores, funcionários 
e comunidade em geral. Para o bom funcionamento de uma rádio-escola é fundamental a colaboração e participação de todos envolvidos direta ou indiretamente. Sendo assim, a escola deve estar aberta ao diálogo e a participação e por meio da comunicação via rádio, promover a integração da escola com a comunidade. Além disso, é preciso aprender novas formas de relacionamento, posturas, iniciativa, criatividade, comunicação, trabalho em equipe.

É extremamente importante repensar a formação do professor e a necessidade da aquisição de novas competências e habilidades para atuar na formação do cidadão capaz de aprender a aprender.

Precisa-se ainda, de gestores e coordenadores escolares mais abertos e comprometidos com a educação, que favoreçam o processo pedagógico, que apoiem professores e funcionários inovadores, afinal todos que trabalham na escola são de certa forma, educadores, pois contribuem para a construção do conhecimento. Desde o porteiro que acompanha de perto o comportamento dos alunos, os serviçais que limpam a escola e preparam o lanche, e os secretários escolares que atendem pais, alunos, professores, além de fazerem o registro da vida escolar dos educandos.

Se gestores e coordenadores dedicassem um pouco mais do seu tempo para ouvirem esses funcionários, perceberiam que estes não permanecem estacionados, totalmente passivos, eles interagem de forma ampla com todos os segmentos da escola e podem se bem preparados, contribuir de forma efetiva na organização da escola.

O conhecimento, sem dúvida, torna-se mais produtivo se o integramos em uma visão ética pessoal que favoreça a participação de todos os envolvidos no processo educacional, transformando-o em sabedoria, em saber pensar para fazer melhor, para incorporar novos pontos de vista, para estabelecer pontes entre a experiência, a teoria e a prática.

Todo indivíduo produz melhor se motivado e integrado ao seu ambiente de trabalho. Enquanto permanecer nas escolas as hierarquias absolutas do "eu mando e você obedece", do "eu sei o 
que é melhor para todos", a competência e iniciativa são aniquiladas e tudo o que se faz é só para impressionar e agradar superiores arrogantes. Moran (2000, p. 25), nos alerta para o fato de que ainda hoje, nas escolas, há mais pessoas voltadas para dentro de si, mais repetidoras do que criadoras, mais desorientadas do que integradas.

Dessa forma, considerando que a escola representa uma comunidade de pessoas empenhadas na melhoria da educação oferecida, é primordial que ela proporcione condições e recursos para uma maior capacidade de iniciativa na sugestão e concretização de atividades e serviços escolares, que proporcione a capacitação adequada de todos os agentes educativos da escola - pessoal docente e não docente.

A escola precisa, inclusive, ser um lugar atraente, um espaço estimulador de aprendizagem e ao mesmo tempo transformador das organizações sociais, políticas e produtivas. Portanto, o gestor competente é aquele que tem ciência que a escola em sua ação global caracteriza-se pela importância da participação consciente e esclarecida das pessoas nas decisões do seu trabalho que deve ser voltado para a construção da excelência em torno dos seus objetivos.

A partir dessas observações, concluímos que a rádio-escola é um recurso pedagógico de grande eficácia, pois tem o poder de politizar os alunos, de transformar a realidade da escola. Quando a rádio entra "no ar" proporciona novas possibilidades de aprendizagem, torna o ambiente mais alegre, os alunos mais participativos.

Observamos que muitos alunos considerados tímidos e sem iniciativa, ao entrarem para a equipe de produção dos programas, se tornaram mais confiantes, participativos, felizes, interessados em aprender e se aproximaram mais dos seus colegas e professores.

Verificamos também, mudanças significativas no relacionamento dos alunos com a administração da escola e com os professores. Estes aprenderam a reivindicar seus direitos, a valorizar seus trabalhos, além de emitir suas opiniões.

O projeto Rádio-escola despertou o interesse de outras escolas da cidade, em fazer uso da rádio como ferramenta de apoio pedagógico, 
o que gerou um intercâmbio cultural entre os alunos, proporcionando a troca de conhecimentos e o cooperativismo educacional.

$\mathrm{E}$, finalmente o uso eficiente da rádio-escola como recurso didático só é possível por meio de uma gestão verdadeiramente democrática voltada para excelência da competência física, humana e técnica.

Da pesquisa emergem indagações que constituirão futuras reflexões a respeito do uso eficiente das TICs na educação. Parecenos que, as principais resistências de professores e administradores ao fazerem uso das tecnologias como recurso pedagógico não estão apenas na falta de preparação desses profissionais no manuseio correto, mas também, nas mudanças que essas ferramentas proporcionam ao ambiente escolar.

\section{Referências}

JÚNIOR, Achylles de Oliveira Costa. Da clandestinidade à legalidade o discurso social sobre as rádios comunitárias. 1999. Dissertação (Mestrado) - ECO/UFRJ, Rio de Janeiro, 1999.

LEMOS, André. Cibercultura, tecnologia e vida social na cultura contemporânea. 2. ed. Porto Alegre: Suinas, 2004.

MORAN, José Manuel. MASETTO, Marcos T. BEHRENS, Marilda Aparecida. Novas tecnologias e mediação pedagógica. 8. ed. Campinas: Papirus, 2000.

PORCHAT, Maria Elisa. Manual de Radiojornalismo Jovem Pan. 3. ed. São Paulo: Ática, 1993. 